\title{
TETX: a novel nuclear selection marker for Chlamydomonas reinhardtii transformation
}

\author{
Sergio A Garcia-Echauri ${ }^{1,2}$ and Guy A Cardineau ${ }^{1,2^{*}}$
}

\begin{abstract}
Background: Transformation of microalgae to obtain recombinant proteins, lipids or metabolites of economic value is of growing interest due to low costs associated with culture growth and scaling up. At present there are only three stable nuclear selection markers for the transformation of Chlamydomonas reinhardtii, which is the most commonly transformed microalgae, specifically: the aminoglycoside phosphotransferaseses aph7and aphVIII and the phleomycin resistance ble gene. As several microalgae are resistant to some of the antibiotics associated with the mentioned resistance genes, we have developed another alternative, tetX, a NADP-requiring Oxidoreductase that hydroxylates tetracycline substrates. We provide evidence that tet $X$ can be used to obtain nuclear transformants of Chlamydomonas reinhardtii.

Results: We obtained nuclear transformants harbouring the tetX gene under the control of beta 2 tubulin or HSP70ARBCS2 promoters at an efficiency of transformation of 3.28 and 6.18 colony forming units/ $\mu \mathrm{g}$ DNA respectively. This is the first report of a eukaryotic cell transformed using tetracycline as a selectable marker.

Conclusions: We developed a protocol for the nuclear transformation of Chlamydomonas reinhardtii using tetX as a selectable marker that confers stable resistance to tetracycline up to $100 \mu \mathrm{g} / \mathrm{mL}$. We believe tetX can be used to transform Chlamydomonas reinhardtii chloroplasts, related microalgae and other aerobic organisms sensitive to any tetracycline antibiotic.
\end{abstract}

Keywords: Chlamydomonas reinhardtii, Tetracycline resistance, Glass bead transformation, tetX

\section{Background}

Genetic transformation of microalgae is of growing interest due to its easy growth and low cost scaling up capabilities [1]. Chlamydomonas reinhardtii is the most commonly used algae for genetic transformations, however it has been less frequently used to produce nucleus derived recombinant proteins due to transgene silencing [2]. At present, through the use of strong promoter/enhancer sequences like HSP70A and RBCS2 [3,4], introns of RBCS2 [5], and fusions with selectable markers $[3,6-8]$, transgene directed protein production in the cytoplasm has increased to $0.25 \%$ of total soluble protein. Although the production levels are still on the order of 10 times lower than comparable production achieved in the chloroplast $[1,3]$, nuclear transformation can produce recombinant proteins that are

\footnotetext{
* Correspondence: guy.cardineau@itesm.mx

${ }^{1}$ Centro de Biotecnología-FEMSA, Tecnológico de Monterrey, Monterrey, México

${ }^{2}$ Centro de Agrobiotecnología, Tecnológico de Monterrey, Monterrey, México
}

post-translationally modified and secreted to the exterior of the cell [4].

There are two main mechanisms used to select $C$. reinhardtii nuclear transformants: either generating auxotrophic mutants and then transforming them with the wild-type gene [9] or incorporating a gene that generates resistance to an antibiotic or herbicide. Generating antibiotic resistance is the most frequently used method. Although many microalgae have been transformed, few nuclear selection markers have been expressed stably in the cytoplasm. Specifically, the available selection marker genes are the aph7 gene from Streptomyces hygroscopicus [10], the Streptomyces rimosus aphVIII [11] and the ble gene from Streptoalloteichus hindustanus. Both aph7 and aphVIII confer resistance to different aminoglycoside antibiotics. The aph7 gene only confers resistance to hygromycin B [10,12], and while aphVIII confers paromomycin resistance 2-10 fold higher than the minimum inhibitory concentration (MIC) to C. reinhardtii, which is adequate to select 
transformants, poor results have been seen with G418, kanamycin and neomycin, which require concentrations on the order of 1.2-1.3 fold higher than MIC for selection. As this is inadequate for selection, paromomycin is the agent of choice used to select transformants [11] Other wild type microalge like Chlorella sorokiniana, Picochlorum sp. Botrycoccus braunii, Tetraselmis suecica, Dunaliella salina are resistant to paromomycin [13] and probably to other aminoglycoside antibiotics. The ble gene generates resistance to phleomycin derived antibiotics [14] such as zeocin, which is the most readily available of that group, however, all the phleomycin antibiotics are expensive. Green algae like Pseudokirchneriella subcapitata, the cyanobacteria like Microcystis aeruginosa, and Anabaena CPB4337 are considered sensitive to tetracycline compounds $[15,16]$. As there is no reported transformation protocol or selectable marker that generates tetracycline resistance in microalgae or any eukaryote, we pursued the development of such a system for the transformation of the model microalgae $C$. reinhardtii.

There are three main resistance mechanisms that confer tetracycline resistance in bacteria: efflux pumps [17], ribosomal protectors [18] and covalent modifiers [19]. Most proteins that confer resistance to tetracycline used in bacterial transformation are membrane bound effector pumps that export tetracycline to the exterior of the cell. Those could be a challenge to express properly in microalgae and other eukaryotic cells due to their association with the bacterial membrane. Ribosomal protectors are large; for example TetM and TetO are each comprised of 639 amino acid (a.a.) residues (Acc. ADV76307, YP_009080033) and because tetracycline prevents the binding of aminoacyl- tRNA with the bacterial ribosome [20], ribosomal protectors would need to be targeted to the chloroplast and/or mitochondria which contain the homologue to the bacterial ribosome in eukaryotes.

Alternatively, Tetx [21,22] is a $43.7 \mathrm{kDa}$ (388 a.a.) NADP-requiring Oxidoreductase that hydroxylates a broad spectrum of tetracycline substrates resulting in unstable compounds that undergo non-enzymatic decomposition [23]. TetX degrades the following compounds: chlortetracycline, demeclocycline, doxycycline, minocycline, oxytetracycline, tetracycline and tigecycline $[23,24]$. This is particularly useful in the generation of transformants harboring the tet $\mathrm{X}$ gene as different organisms have distinct sensitivity to each compound, for example, the protozoan Toxoplasma gondi is sensitive to doxycycline and resistant to tetracycline [25], the pathogenic yeast Candida albicans is also resistant to tetracycline and sensitive to minocycline and tigecycline [26-28].

Tetracycline resistance used to select genetically modified organisms has been present since the dawn of recombinant DNA technology $[29,30]$, however until this report its use as a selection marker was restricted to bacteria. We designed a synthetic tetX gene for expression in the eukaryotic model microalgae $C$. reinhardtii and describe a nuclear transformation protocol for Chlamydomonas reinhardtii using tet $\mathrm{X}$ that generates tetracycline resistance. This is the first report of a genetically modified eukaryote selected with tetracycline. We compare the transformation efficiency of tet $\mathrm{X}$ under two promoters, beta 2 tubulin and the HSP70ARBCS2, with that of two commonly used selection markers, the aphVIII gene controlled by the beta 2 tubulin promoter and the ble gene controlled by the RBCS2 promoter. We also performed tetracycline resistance stability assays of transformants grown in the absence of antibiotic.

\section{Results}

\section{TetX genes}

We synthetized a tet $\mathrm{X}$ open reading frame codon optimized for expression in C. reinhardtii cytoplasm, driven by the beta 2 tubulin promoter [31] and with chlamyopsin 1 3' UTR [11] We named this construct BtetX (Figure 1). A second version with tetX under HSP70A/RBCS2 enhancer/ promoter containing one intron copy of RBCS2 intron 1 and RBCS2 3'UTR was assembled and correct fragments verified by restriction digestion (Data not shown). That plasmid was named AtetX. Plasmid characteristics can be reviewed in Table 1.

\section{TetX transformants were obtained for both constructs}

Transformations with both constructs were carried out and, 8-12 days after plating transformed cells, tetracycline resistant $C$. reinhardtii colonies appeared. Both promoters used to drive tet $X$ expression yielded transformant colonies, which indicates the versatility of this system to work with low and high level expression promoters (Figure 2).

\section{Transformation efficiency}

As expected, the HSP70A/RBCS2 enhancer/promoter yielded more colonies than the $\beta$-tubulin promoter. In 3 independent transformations the average number of colonies per plate was $20 \pm 2.08$ and $9 \pm 0.57$ respectively. The calculated efficiency was $6.18 \mathrm{cfu} / \mu \mathrm{g}$ of DNA for AtetX and 3.28 for BtetX. The efficiency was similar to that of pKS-aphVIII at 4.51 and lower than the ble gene with 22.56 (Table 1). We believe the lower efficiency of AtetX compared to the ble gene is caused by the addition of an extra RBCS2 intron 1 within the sequence of the ble gene, as this extra intron increased the efficiency 3 times compared to a ble gene with only one intron [5].

\section{Effect of light intensity and cell concentration on false positive transformants}

As light causes tetracycline degradation, we analyzed the relationship between the appearance of resistant positive 


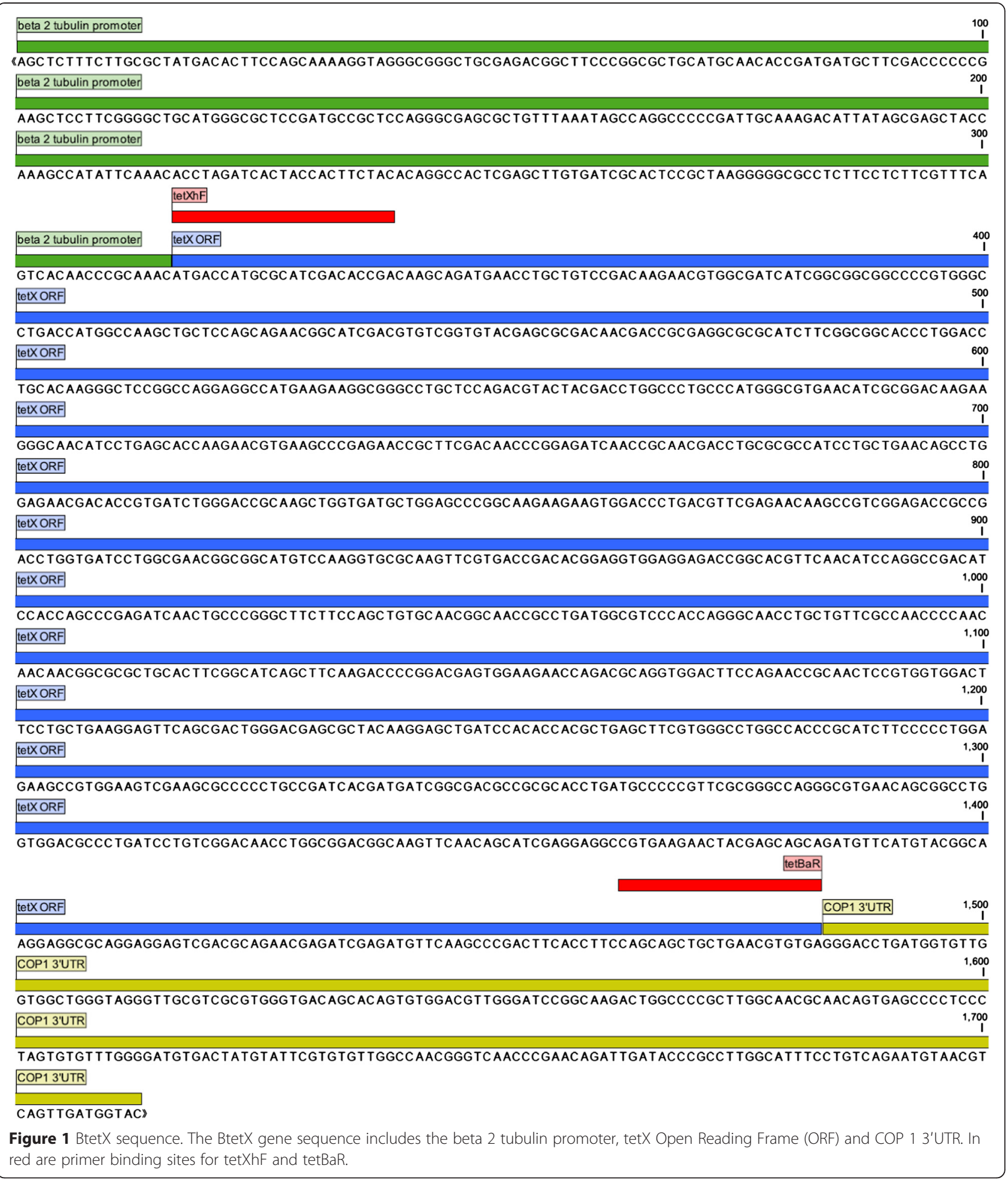

or false positive colonies with respect to cell concentration per plate and light intensity (Table 2). When $5 \times 10^{6}$ cells/plate were grown under medium light conditions (17-25 $\mu$ moles $\mathrm{m}^{-2} \mathrm{~s}^{-1}$ ), tetracycline at $15 \mu \mathrm{g} / \mathrm{mL}$ was sufficient to prevent false positives from growing on selection plates. All transformants selected at these conditions were positive. However at concentrations above $5 \times 10^{6}$ cells/plate, and/or light intensity above $27 \mu$ moles $\mathrm{m}^{-2} \mathrm{~s}^{-1}$, false positives appeared as either a lawn or patches of small colonies. However because positive colonies grow faster than negative transformants, they can be easily distinguished and selected from the small colony false 
Table 1 Plasmids used to transform C. reinhardtii

\begin{tabular}{llllll}
\hline Plasmid & Promoter/terminator/\#RBCS2 introns & Resistance & Base pairs/MW $\mathbf{( g / m o l )}$ & TE & Source \\
\hline AtetX & HSP70A:RBCS2/RBCS2/1 & Tetracycline & $5238 / 3236640.1$ & 6.18 & This work \\
BtetX & B-2 tubulin/COP-1/NO & Tetracycline & $4445 / 2746642.9$ & 3.28 & This work \\
pKs-aphVIII & $\beta-2$ tubulin/COP-1/NO & Paromomycin & $4308 / 2661961.7$ & 4.51 & {$[38]$} \\
psP124S-ble & RBCS2/RBCS2/2 & Zeocin & $4133 / 2553770$ & 22.56 & {$[5]$} \\
\hline
\end{tabular}

Listing of plasmids used in this work with their corresponding promoter/terminator/number of RBCS2 introns, associated resistance, plasmid size, molecular weight (MW) and Transformation Efficiency (TE).

positives. Positive transformants can be grown on plates containing tetracycline concentrations up to $100 \mu \mathrm{g} / \mathrm{mL}$. We also assayed tetracycline concentrations of 25 and $50 \mu \mathrm{g} / \mathrm{mL}$ to select primary transformants, however, at those concentrations the number of positive colonies decreased approximately $75 \%$ compared to those obtained with $15 \mu \mathrm{g} / \mathrm{mL}$ (data not shown).

\section{Transformants grown with no antibiotic retained tetracycline resistance}

Nuclear transgene silencing in $C$. reinhardtii has caused loss of resistance phenotype in half of aadA transformants that conferred spectinomycin or streptomycin resistance [32], which is why it is not routinely used for selection. We therefore assayed tetracycline resistance when positive transformed strains expressing the tet $X$ gene were grown without antibiotic (Figure 3). Antibiotic resistance was maintained at minimum for 26 divisions, and transformants were also resistant to concentrations up to $100 \mu \mathrm{g} / \mathrm{mL}$ (Figure 3).

\section{Wild type cell-walled C. reinhardtii strain is sensitive to tetracycline}

Because we used a cell wall deficient strain for transformation and selection, we tested sensitivity to tetracycline using a wild type (WT) cell-walled strain, CC-124, in order to evaluate more general utility. We therefore grew strain CC-124 in TAP agar plates, under the same light conditions used for transformation, tetracycline concentrations of 15,25 and $50 \mu \mathrm{g} / \mathrm{mL}$, and cell concentrations from $0.51 .0,2.5$ and $5.0 \times 10^{6}$ cells per plate. After a period of 10 days, the time required for transformants to become visible, we found no growth of wild type cells. This suggests that tetracycline uptake at the assayed concentrations is not sufficiently affected by the wild type cell-wall to alter the sensitivity of the cells to tetracycline and that tetracycline selection could work with normal cell-walled wild type cells.

\section{Conclusions}

We have developed a new stable nuclear selection marker for $C$. reinhardtii that confers resistance to tetracycline at up to $100 \mu \mathrm{g} / \mathrm{mL}$. Although tetracycline is light sensitive and acts in the chloroplast, this was not an obstacle to develop an efficient method to obtain transformants. Compared with hygromycin B, paromomycin and zeocin, tetracycline is by far the least expensive antibiotic (Gold biotechnology, Inc. St. Louis, MO, USA) and provides a reasonable alternative selectable agent for transformation of microalgae. As tet $\mathrm{X}$ hydrolyzes several tetracycline analogues, [23,33] their use might favor increased light incubation to obtain transformants. We believe that the tet $X$ gene produces a versatile tetracycline degrading enzyme, which suggests it could be used to transform the nucleus of other microalgae, as well as the chloroplast or mitochondria of other tetracycline sensitive cells, such as Saccharomyces cerevisiae or human HeLa cells that are sensitive to tetracycline concentrations above $10 \mu \mathrm{g} / \mathrm{mL}[34,35]$. Codon bias

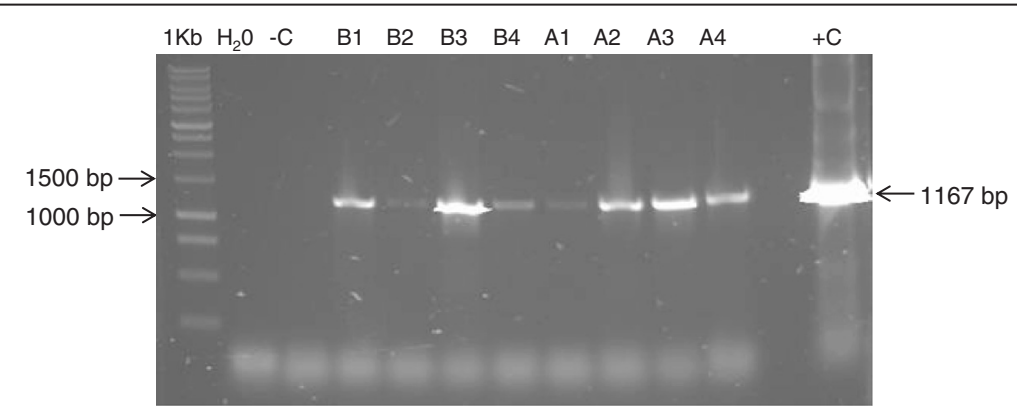

Figure 2 TetX gene presence in AtetX and BtetX transformants. 1\% TAE-agarose gel of colony PCR of tetracycline resistant colonies transformed with AtetX (A1-4) or BtetX (B1-4). 1 kb: 1 kb DNA ruler, $\mathrm{H}_{2} \mathrm{O}$ : water was used instead of DNA template, -C: DNA from an untransformed cc-849 strain was used as negative control, +C: AtetX plasmid was used as template. 
Table 2 Effect of light intensity and cell concentration on false positive appearance

\begin{tabular}{llll}
\hline Cells $/$ plate & \multicolumn{3}{l}{ Light intensity $\left(\mu\right.$ moles $\left.\mathbf{~ m}^{-\mathbf{2}} \mathbf{s}^{-\mathbf{1}}\right)$} \\
\cline { 2 - 4 } & $\mathbf{1 7}$ & $\mathbf{2 4}$ & $>\mathbf{2 6}$ \\
\hline $2.5 \times 10^{6}$ & - & - & + \\
$5.0 \times 10^{6}$ & - & - & + \\
$1.0 \times 10^{7}$ & - & + & + \\
$3.0 \times 10^{7}$ & + & + & + \\
\hline
\end{tabular}

We measured the appearance of false positives on tet $\mathrm{X}$ transformed $\mathrm{C}$. reinhardtii plates when grown at different cell concentrations and light intensities: (-) indicates no false positives, (+) indicates presence of false positives.

of the specific target host and organelle may need to be considered to optimize expression.

\section{Methods}

Algal strain and growth conditions

Cell wall deficient strain CC-849 of Chlamydomonas reinhardtii (Chlamydomonas Resource Center, University of Minnesota) was used in all algal transformation experiments. We chose this strain because it is readily transformed with glass beads or electroporation. Strain CC-124 (Chlamydomonas Resource Center) was used as a control to assay tetracycline sensitivity of WT cell wall strains. All algal strains were grown routinely in TAP media [36] at $25^{\circ} \mathrm{C}$ with a $16 / 8$ light/dark photoperiod in a growth chamber on top of translucid glass shelves. In front of the shelves, two pairs of Sylvania GRO-LUX $40 \mathrm{~W}$ wide spectrum fluorescent light tubes (Osram sylvania ltd. Mississauga, ON, CA) and two OCTRON ECO $32 \mathrm{~W}$ fluorescent light tubes (Osram sylvania ltd) placed perpendicular to the shelve provided for light. Plates were placed at 3 to $40 \mathrm{~cm}$ from the light source which provided light from 78.6 to $25 \mu$ moles $\mathrm{m}^{-2} \mathrm{~s}^{-1}$. Light intensity was measured with a LI-250A light meter (LI-COR, Lincoln, NE, USA), readings are the sum of 15 second averages from two positions: placing the sensor on top of the glass shelf targeted at the ceiling and at the same place with the sensor targeted towards the floor. To achieve lower than $25 \mu$ moles $\mathrm{m}^{-2} \mathrm{~s}^{-1}$, plates were placed in front of only one pair of Sylvania GRO-LUX $40 \mathrm{~W}$ wide spectrum fluorescent light tubes at $30-40 \mathrm{~cm}$ from the light source. The lowest light setting: $1.81 \mu$ moles $\mathrm{m}^{-2} \mathrm{~s}^{-1}$, was achieved by placing the plates in the lowest light location in the growth chamber $\left(17 \mu\right.$ moles $\left.\mathrm{m}^{-2} \mathrm{~s}^{-1}\right)$ and covering the plates with two double-layers of gauze.

\section{Plasmid construction}

E. coli strains carrying Plasmids $\mathrm{pHsp70A/RbcS2-cgLuc}$ [7,37], pSP124S ble cassette [5] and pKS-aphVIII-lox [38] were obtained from the Chlamydomonas Resource Center.

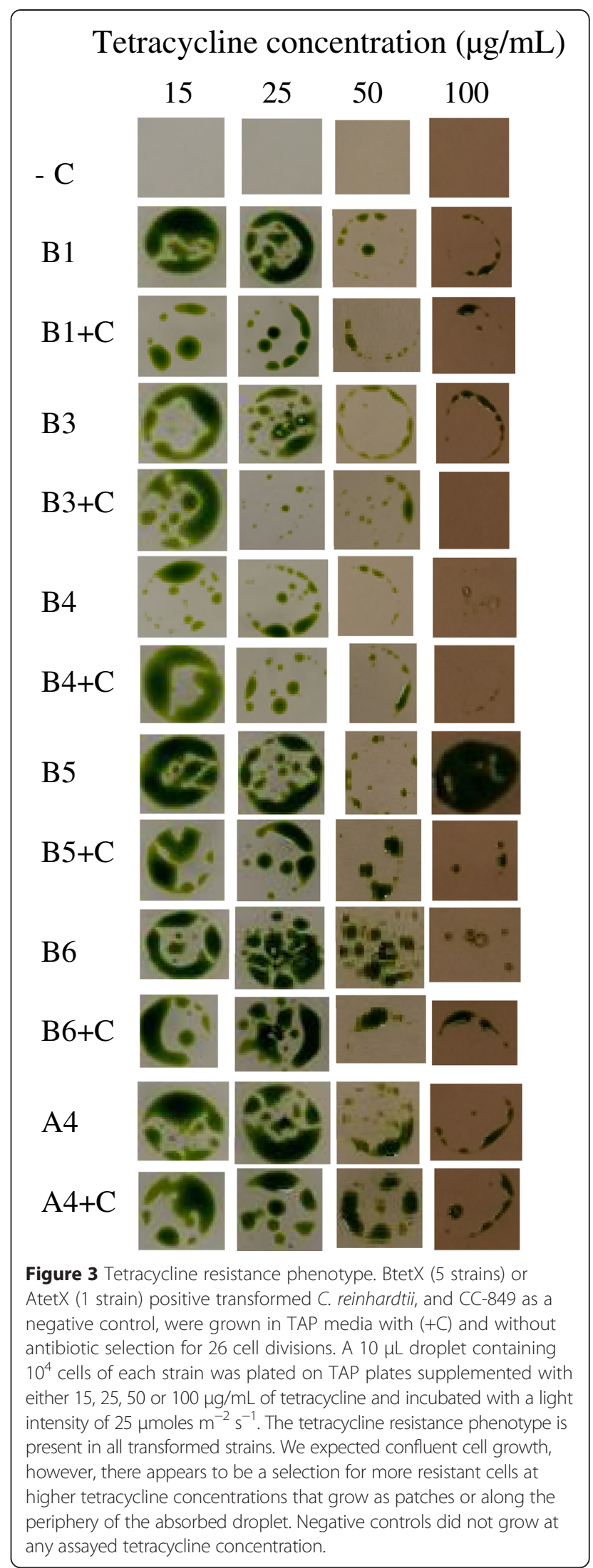


TetX open reading frame [native sequence from $E n-$ terobacteriaceae bacterium; Genbank: JQ990987] was synthesized de novo at GenScript (Piscataway, NJ, USA) with codons optimized for Chlamydomonas reinhardtii cytoplasmic expression under the control of constitutive beta 2 tubulin promoter [31] and chlamyopsin1 3'UTR [11]; the plasmid was named Btetx (Figure 1). A second version of the construct was generated by Polymerase Chain Reaction (PCR), amplifying the open reading frame with a Veriti thermal cycler (Applied Biosystems, Foster City, CA, USA) in a $25 \mu \mathrm{L}$ reaction volume containing $1 \mathrm{U}$ of the proof-reading high fidelity ( 1 error $/ 100,000 \mathrm{bp}=0.001 \%$ ) enzyme Advantage HD DNA Polymerase (Clontech, Palo alto, USA), $0.1 \mathrm{mM}$ dNTP's, and $0.25 \mu \mathrm{M}$ of each oligo tetXhF and tetBaR (Table 3) that carried XhoI and BamHI sites in their $5^{\prime}$ ends for cloning purposes. The reaction was carried out with an initial denaturation at $98^{\circ} \mathrm{C}$ $2 \mathrm{~min}$. following 35 cycles of $98^{\circ} \mathrm{C} 10 \mathrm{sec}, 70^{\circ} \mathrm{C} 10 \mathrm{sec}$, $72^{\circ} \mathrm{C} 1 \mathrm{~min}$. with a final $5 \mathrm{~min}$ extension at $72^{\circ} \mathrm{C}$. The amplicon was digested with BamHI and XhoI (New England Biolabs, Ipswich, MA, USA), and cloned into the corresponding sites of plasmid pHsp70A/RbcS2cgLuc, replacing the luciferase ORF with that of tetX. The ligation was transformed into E. coli stbl4 (Invitrogen, Carlsbad, CA, USA) generating plasmid AtetX.

\section{Glass bead transformation}

C. reinhardtii strain CC-849 was transformed with supercoiled plasmid DNA of Atetx, Btetx, pKS-aphVIII or pSP124S (Table 1) by the glass bead method [39]. Briefly, the algae were grown at $25^{\circ} \mathrm{C}$ with a $18 / 6$ (light/dark) photoperiod in TAP media to mid-log phase $\left(1-2 \times 10^{6}\right.$ cells $\left./ \mathrm{mL}\right)$, the cells were harvested by centrifugation $5 \mathrm{~min}$. at $5000 \times \mathrm{G}$, the growth medium was removed and fresh TAP was added to achieve a cell concentration of $2 \times 10^{8}$ cells/ mL. $300 \mu \mathrm{L}$ of the cell suspension were placed in a $1.5 \mathrm{~mL}$ centrifuge tube containing $0.3 \mathrm{~g}$ of sterile $0.4-0.6 \mathrm{~mm}$ diameter glass beads (Sigma, St. Louis, MO, USA) and $1 \times 10^{-12}$ mols of the desired plasmid DNA. The cell/ DNA/glass bead suspensions were vortexed $15 \mathrm{~s}$ at maximum power in a VWR mini vortex. The cells were

\section{Table 3 Oligonucleotides used}

\begin{tabular}{ll}
\hline Name & Sequence $\mathbf{5}^{\prime}$-3' \\
\hline aph8F & CGTGCACTGCGGGGTCGGT \\
aph8R & CCGCCCCATCCCACCCGC \\
ble1F & CCGGGTCGCGCAGGGC \\
ble1R & GCGCCGTTCCGGTGCTCA \\
tetXhF & TCTCGAGATGACCATGCGCATCGACACCGA \\
tetBaR & TGGATCCTCACACGTTCAGCAGCAGCTGCTG
\end{tabular}

Listing of oligonucleotides used in this work. Bases in bold indicate recognition sites for restrictions enzymes and accessory bases used for cloning purposes. transferred to a glass tube with $5 \mathrm{~mL}$ of fresh TAP media and incubated at $25^{\circ} \mathrm{C}$ overnight with a $8 / 6$ (light/dark) photoperiod. After 14 hours the cells were concentrated by centrifugation at $5,000 \times \mathrm{g}$ for 15 minutes and resuspended in TAP media to yield either $3 \times 10^{7}$ cells $/ \mathrm{mL}$ of pKS-aphVIII and pSP124S transformants and $2.5 \times 10^{6}$, $5 \times 10^{6}, 1 \times 10^{7}$ or $3 \times 10^{7}$ cells $/ \mathrm{mL}$ for tet $\mathrm{X}$ transformants. $300 \mu \mathrm{L}$ of the cell suspensions were spread on $100 \mathrm{~mm}$ diameter and $15 \mathrm{~mm}$ depth TAP agar plates supplemented with either $150 \mu \mathrm{g} / \mathrm{mL}$ paromomycin, $20 \mu \mathrm{g} /$ $\mathrm{mL}$ Zeocin or $15 \mu \mathrm{g} / \mathrm{mL}$ tetracycline. Plates were incubated at $25^{\circ} \mathrm{C}$ with a $18 / 6$ (light/dark) photoperiod in low light $\left(1.81 \mu\right.$ moles $\left.\mathrm{m}^{-2} \mathrm{~s}^{-1}\right)$ for $1 \mathrm{day}$, and then tet $\mathrm{X}$ plates were transferred to medium light $\left(25 \mu\right.$ moles $\left.\mathrm{m}^{-2} \mathrm{~s}^{-1}\right)$ while paromomycin and zeocin plates were incubated in high light $\left(78.6 \mu\right.$ moles $\left.\mathrm{m}^{-2} \mathrm{~s}^{-1}\right)$ When colonies appeared, they were streaked on to selective TAP agar plates.

\section{PCR confirmation of transformants}

To verify the gene presence in transformants, colony PCR [40] was performed in a $15 \mu \mathrm{L}$ reaction volume containing $7.5 \mu \mathrm{L}$ of GoTaq Green Master Mix (Promega, Madison Wi, USA) , $0.25 \mu \mathrm{M}$ of each appropriate oligo pair: aph8F, aph8R; ble1F, ble1R; tetXhF, tetBaR (Table 3). An initial 5 minute denaturation at $95^{\circ} \mathrm{C}$ was performed, followed by 35 cycles of $95^{\circ} \mathrm{C} 20 \mathrm{sec}, 60-70^{\circ} \mathrm{C} 15 \mathrm{sec}, 72^{\circ} \mathrm{C} 1 \mathrm{~min}$ with a final $5 \mathrm{~min}$ extension at $72^{\circ} \mathrm{C}$. The amplicons were resolved in a $1 \%$ TAE-agarose gel stained with Sybr safe (Invitrogen, Carlsbad, CA, USA). Positive colonies confirmed by PCR were counted and the efficiency reported as colony forming units (cfu) per $\mu \mathrm{g}$ of DNA.

\section{Tetracycline sensitivity resistance assays}

Five random strains of BtetX, one of AtetX and one of CC-849 untransformed control were selected from TAPagar plates and $10^{4}$ cells of each strain were grown in $2 \mathrm{~mL}$ TAP media without tetracycline. Positive controls were grown on TAP agar plates supplemented with $15 \mu \mathrm{g} / \mathrm{mL}$ tetracycline. After five days, cell concentration of the cultures was $1 \times 10^{7}$ cells $/ \mathrm{mL}$ which corresponds to 26 cell divisions. At that time, cultures of strains grown with or without antibiotic were diluted with TAP media to $1 \times 10^{6}$ cells $/ \mathrm{mL}$, and $10 \mu \mathrm{L}\left(10^{4}\right.$ cells $)$ of each strain were grown on TAP agar plates containing tetracycline at $15,25,50$ and $100 \mu \mathrm{g} / \mu \mathrm{L}$. After 7 days of growth at a light intensity of $25 \mu$ moles $\mathrm{m}^{-2} \mathrm{~s}^{-1}$ photographs were taken of each plate.

\section{Wild type C. reinhardtii tetracycline sensitivity}

C. reinhardtii strain CC-124 (wt, $\mathrm{mt}-$ ) was grown in TAP agar supplemented with tetracycline concentrations of 15,25 or $50 \mu \mathrm{g} / \mathrm{mL}$, and cell concentrations from 0.5 1.0, 2.5 and $5.0 \times 10^{6}$ cells per plate, incubated for 10 days at a light intensity of $25 \mu$ moles $\mathrm{m}^{-2} \mathrm{~s}^{-1}$. 


\section{TetX plasmid deposit}

The TetXA and TetXB transformation plasmids have been deposited with the Chlamydomonas Resource Center, University of Minnesota.

\section{Competing interests}

The authors declare that they have no competing interests.

\section{Authors' contributions}

SAG-E and GAC conceived, designed the experiments, and helped to draft the manuscript. SAG-E performed all experiments. Both authors read and approved the final manuscript.

\section{Acknowledgements}

The authors thank CONACyT for scholarship 209658 to SAG-E and the Cátedra de Agrobiotecnología, Tecnologico de Monterrey, for economic support.

\section{Received: 12 December 2014 Accepted: 12 March 2015} Published online: 15 April 2015

\section{References}

1. Specht E, Miyake-Stoner S, Mayfield SP. Micro-algae come of age as a platform for recombinant protein production. Biotechnol Lett. 2010;32:1373-83.

2. Cerutti $H$, Johnson AM, Gillham NW, Boynton JE. Epigenetic silencing of a foreign gene in nuclear transformants of Chlamydomonas. Plant Cell. 1997;9:925-45.

3. Rasala BA, Lee PA, Shen Z, Briggs SP, Mendez M, Mayfield SP. Robust Expression and Secretion of Xylanase1 in Chlamydomonas reinhardtii by Fusion to a Selection Gene and Processing with the FMDV 2A Peptide. PLoS One. 2012;7:e43349.

4. Eichler-Stahlberg A, Weisheit W, Ruecker O, Heitzer M. Strategies to facilitate transgene expression in Chlamydomonas reinhardtii. Planta. 2009;229:873-83.

5. Lumbreras $V$, Stevens D, Purton S. Efficient foreign gene expression in Chlamydomonas reinhardtii mediated by an endogenous intron. Plant J. 1998:14(February):441-7.

6. Fuhrmann M, Oertel W, Hegemann P. A synthetic gene coding for the green fluorescent protein (GFP) is a versatile reporter in Chlamydomonas reinhardtii. Plant J. 1999;19:353-61.

7. Fuhrmann M, Hausherr A, Ferbitz L, Schödl T, Heitzer M, Hegemann P. Monitoring dynamic expression of nuclear genes in Chlamydomonas reinhardtii by using a synthetic luciferase reporter gene. Plant Mol Biol. 2004:55:869-81.

8. Rasala BA, Barrera DJ, Ng J, Plucinak TM, Rosenberg JN, Weeks DP, et al. Expanding the spectral palette of fluorescent proteins for the green microalga Chlamydomonas reinhardtii. Plant J. 2013;74:545-56.

9. Debuchy $R$, Purton S, Rochaix JD. The argininosuccinate lyase gene of Chlamydomonas reinhardtii: an important tool for nuclear transformation and for correlating the genetic and molecular maps of the ARG7 locus. EMBO J. 1989:8:2803-9.

10. Berthold P, Schmitt R, Mages W. An Engineered Streptomyces hygroscopicus aph 7"Gene Mediates Dominant Resistance against Hygromycin B in Chlamydomonas reinhardtii. Protist. 2002;153(December):401-12.

11. Sizova I, Fuhrmann M, Hegemann P. A Streptomyces rimosus aphVIII gene coding for a new type phosphotransferase provides stable antibiotic resistance to Chlamydomonas reinhardtii. Gene. 2001:277:221-9.

12. Blochlinger $K$, Diggelmann $H$. Hygromycin B phosphotransferase as a selectable marker for DNA transfer experiments with higher eucaryotic cells. Mol Cell Biol. 1984:4:2929-31.

13. Díaz-Santos E, de la Vega M, Vila M, Vigara J, León R. Efficiency of different heterologous promoters in the unicellular microalga Chlamydomonas reinhardtii. Biotechnol Prog. 2013;29:319-28.

14. Stevens DR, Rochaix JD, Purton S. The bacterial phleomycin resistance gene ble as a dominant selectable marker in Chlamydomonas. Mol Gen Genet. 1996;251:23-30.

15. Van der Grinten E, Pikkemaat MG, van den Brandhof E-J, Stroomberg GJ, Kraak MHS. Comparing the sensitivity of algal, cyanobacterial and bacterial bioassays to different groups of antibiotics. Chemosphere. 2010;80:1-6.

16. González-Pleiter M, Gonzalo S, Rodea-Palomares I, Leganés F, Rosal R, Boltes $\mathrm{K}$, et al. Toxicity of five antibiotics and their mixtures towards photosynthetic aquatic organisms: implications for environmental risk assessment. Water Res. 2013;47:2050-64.
17. Li X-Z, Nikaido H. Efflux-mediated drug resistance in bacteria. Drugs. 2004:64:159-204

18. Dönhöfer A, Franckenberg S, Wickles S, Berninghausen O, Beckmann R, Wilson DN. Structural basis for TetM-mediated tetracycline resistance. Proc Natl Acad Sci U S A. 2012;109:16900-5.

19. Yu Z, Reichheld SE, Cuthbertson L, Nodwell JR, Davidson AR. Characterization of tetracycline modifying enzymes using a sensitive in vivo reporter system. BMC Biochem. 2010;11:34

20. Chopra I, Roberts M. Tetracycline Antibiotics : Mode of Action, Applications, Molecular Biology, and Epidemiology of Bacterial Resistance Tetracycline Antibiotics: Mode of Action, Applications, Molecular Biology, and Epidemiology of Bacterial Resistance. Microbiol Mol Biol Rev. 2001;65:232-60

21. Guiney DG, Hasegawa P, Davis CE. Expression in Escherichia coli of cryptic tetracycline resistance genes from bacteroides $R$ plasmids. Plasmid. 1984;11:248-52.

22. Speer BS, Bedzyk L, Salyers AA. Evidence that a novel tetracycline resistance gene found on two Bacteroides transposons encodes an NADP-requiring oxidoreductase. J Bacteriol. 1991;173:176-83.

23. Yang W, Moore IF, Koteva KP, Bareich DC, Hughes DW, Wright GD. TetX is a flavin-dependent monooxygenase conferring resistance to tetracycline antibiotics. J Biol Chem. 2004;279:52346-52.

24. Moore IF, Hughes DW, Wright GD. Tigecycline is modified by the flavin-dependent monooxygenase TetX. Biochemistry. 2005;44:11829-35.

25. Chang HR, Comte R, Pechère JC. In vitro and in vivo effects of doxycycline on Toxoplasma gondii. Antimicrob Agents Chemother. 1990;34:775-80.

26. Lavarde V, Acar JF, Drouhet E. Effect of minocycline on Candida albicans. "In vitro" study: comparison with tetracycline. Pathol Biol (Paris). 1975;23:725-8.

27. Waterworth PM. The effect of minocycline on Candida albicans. J Clin Pathol. 1974;27:269-72

28. Ku TSN, Palanisamy SKA, Lee SA. Susceptibility of Candida albicans biofilms to azithromycin, tigecycline and vancomycin and the interaction between tigecycline and antifungals. Int J Antimicrob Agents. 2010;36:441-6.

29. Cohen SN, Chang AC, Hsu L. Nonchromosomal antibiotic resistance in bacteria: genetic transformation of Escherichia coli by R-factor DNA. Proc Natl Acad Sci U S A. 1972:69:2110-4

30. Cohen SN, Chang AC, Boyer HW, Helling RB. Construction of biologically functional bacterial plasmids in vitro. Proc Natl Acad Sci U S A. 1973;70:3240-4.

31. Davies JP, Weeks DP, Grossman AR. Expression of the arylsulfatase gene from the $\beta 2$-tubulin promoter in Chlamydomonas reinhardtii. Nucleic Acids Res. 1992;20:2959-65.

32. Cerutti H, Johnson AM, Gillham NW, Boynton JE. A Eubacterial Gene Conferring Spectinomycin Resistance on. Genetics. 1997;145:97-110.

33. Rose WE, Rybak MJ. Tigecycline: first of a new class of antimicrobial agents. Pharmacotherapy. 2006;26:1099-110.

34. Garí E, Piedrafita L, Aldea M, Herrero E. A set of vectors with a tetracycline-regulatable promoter system for modulated gene expression in Saccharomyces cerevisiae. Yeast. 1997:13:837-48.

35. Gossen M, Bujard H. Tight control of gene expression in mammalian cells by tetracycline-responsive promoters. Proc Natl Acad Sci U S A. 1992;89:5547-51.

36. Harris EH. The Chlamydomonas Sourcebook. A Comprehensive Guide to Biology and Laboratory Use. San Diego, CA: Academic Press. 1989. xiv, 780 pp., illus.

37. Ruecker O, Zillner K, Groebner-Ferreira R, Heitzer M. Gaussia-luciferase as a sensitive reporter gene for monitoring promoter activity in the nucleus of the green alga Chlamydomonas reinhardtii. Mol Genet Genomics. 2008;280:153-62

38. Heitzer M, Zschoernig B. Construction of modular tandem expression vectors for the green alga Chlamydomonas reinhardtii using the Cre/lox-system. Biotechniques. 2007:43:324-32.

39. Kindle KL. High-frequency nuclear transformation of Chlamydomonas reinhardtii Proc Natl Acad Sci U S A. 1990;87:1228-32.

40. Cao M, Fu Y, Guo Y, Pan J. Chlamydomonas (Chlorophyceae) colony PCR. Protoplasma. 2009;235:107-10. 